\title{
A Preliminary Research on a Plasma Spout-Fluid Bed Reactor
}

\author{
L. Tang ${ }^{1 *}$, H. Huang ${ }^{2}$, X. Yang ${ }^{1}$, H. Hao ${ }^{1}$, K. Zhao ${ }^{1}$ \\ ${ }^{1}$ Department of Civil Engineering, Guangzhou University, Waihuanxi Road, Guangzhou, China \\ ${ }^{2}$ Department of Environmental Engineering, Guangdong University of Technology, Waihuanxi Road, Guangzhou, China
}

Received February, 2013

\begin{abstract}
A laboratory-scale plasma spout-fluid bed reactor with a $10 \mathrm{~kW}$ DC plasma torch was developed and tested using quartz sand particle and rice hull. The preliminary experimental results including particle recirculation and attrition, bed temperature distribution and stability, as well as biomass gasification system energy balance were presented in this paper. Research results indicated that plasma spout-fluid bed reactor may be a technically feasible reactor for carbonaceous organic material gasification.
\end{abstract}

Keywords: Thermal Plasma; Spout-fluid Bed; Gasification

\section{Introduction}

Thermal plasma pyrolysis/gasification is an innovation technology for transforming high calorific waste streams such as organic solid waste into a valuable synthesis gas and a vitrified slag [1-3]. Up to now thermal plasma pyrolysis/gasification technology was applied only to destroy highly toxic compounds and to modify refractory compound [4-5]. Thermal plasma pyrolysis/gasification of solid waste for energy and chemical recycling are seldom practiced for technical and economic reasons $[6,7]$.

Spout-fluid bed reactor is a combination of a fluidized bed and spouted bed by combining the fluid flow of the single central opening (spouted bed) with the auxiliary fluid flow through the distributor plate (fluidized bed). Spout-fluid bed reactors used for combustion or gasification are reported to overcome the limitation of spouted bed and fluidized bed by providing higher rate of mixing, better solid fluid contact, even fluid flow distribution resulting to the minimization of dead zones, better solid fluid contact, improved mass and heat transfer characteristics [8]. The basic principal of the plasma spout-fluid bed reactor is essentially similar to that of a standard spouted bed. The main difference, however, lies in the fact that the spouting gas is substituted by a DC plasma jet which discharges in the conical bottom of the reactor. This has the main advantage that the radiation and convection losses from the plasma are recuperated by the solid charge of the reactor thus giving rise to substantially higher energy efficiencies.

In this research, a DC plasma jet forms the spout which provides heat for the process and this spout is surrounded by a conventional fluidized bed. Plasma spouted and spout-fluid beds have been reported [9], but very little attention has been given ever since to the study of its operating characteristics and the basic phenomena involved. It is essential to this end, that the present study has been conducted with the objective of obtaining basic information about such phenomena as, spouting stability, particle attrition and elutriation from the bed, temperature distribution and energy balance. The overall objective of this work was to assess the technical feasibility of using a plasma spout-fluid bed to carry out a biomass gasification to recover energy and resource.

\section{Experimental}

The experimental apparatus is shown schematically in Figure 1. The rectifier, which provides DC power to the plasma torch is rated at $10 \mathrm{~kW}$. The plasma torch is of the standard configuration with a conical tungsten cathode and annular copper anode between which the plasma forming gases pass. The torch current (and thus power) and gas flow rates are controlled at the control panel. The gasification reactor comprised a cylindrical column part fitted to a conical base which coupled with the DC plasma torch. The column has an inside diameter of 200 $\mathrm{mm}$ and a height of $500 \mathrm{~mm}$, it is made of quartz for observational study conveniently. The total angle of the cone is $60^{\circ}$ and the diameter of the plasma torch orifice is $8 \mathrm{~mm}$. A variable-speed screw feeder situated on the top of the quartz tube ensured that the particles were fed toward the cylindrical quartz reactor. A water bath is 


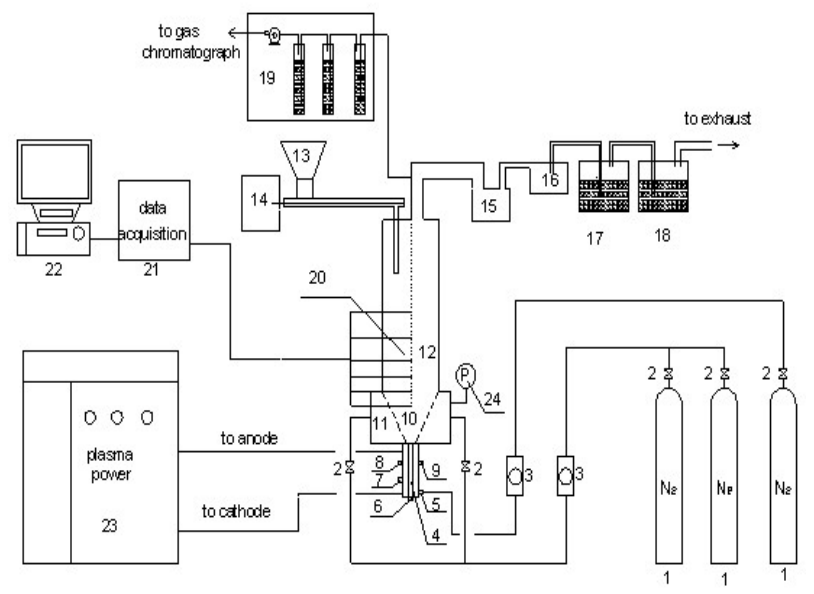

1.nitrogen gas cylinder 2. flow valve 3. flow meter 4. plasma torch 5.6. cooling water inlet 7. plasma gas inlet 8.9. cooling water outlet 10 . cone 11 . fluid gas plenum chamber 12. cylinder 13. feed hopper 14. control system of screw feeder 15 . cyclone separator 16 . filter 17.18 . water scrubber 19. gas sampling system 20. thermal couple 21. data acquisition system 22.computer 23. plasma power source 24. pressure gage

Figure 1. Schematic of the plasma spout-fluid experimental apparatus.

provided to filter the micron particles and cool the reactor exhaust gases before they reach the sample bag or be exhausted.

Two sources of $\mathrm{N}_{2}$ flow to the bed, the spouting gas is provided by a DC plasma jet. Fluidizing $\mathrm{N}_{2}$ enter the distributor which contains 300 holes (1 mm in diameter) evenly distributed at the wall of the cone; the purpose of the fluidizing gas is to provide gasifying agent such as oxygen, water steam or air to the reactor, fluidifying the reactant as well as cooling the reactor wall. The particle used in our experiments is quartz sand with the mean particle size of $200 \mu \mathrm{m}$ and rice hull with the mean particle size of $350 \mu \mathrm{m}$.

The temperature distribution inside the bed is obtained using $25 \mathrm{~K}$-type thermocouples placed at different levels in the bed. In addition, a K-type thermocouple is set above the bed for measuring the gas outlet temperature. The data are recorded by a data acquisition system. The temperature image of the quartz reactor wall was obtained using a thermal infrared imager (TH9100 wv, NEC, Japan).

\section{Results and Discussion}

\subsection{Particle Attrition}

A special attention was given to the question of particle attrition in the bed. Samples of the bed charge were taken before and after plasma treatment and were subject to particle size analysis. Results reveal a substantial change in the quartz sand particle size distribution after only a 10 minutes treatment in the plasma at a power level of 10 $\mathrm{kW}$. The influence of the operating parameters on the attrition rate was not studied.

This could be attributed to attrition due to particleparticle or particle-reactor internal face collision or simply thermal shock of the quartz sand as the particles are exposed to the high plasma temperatures during their short flight in the fountain region of the spout-fluid bed.

\subsection{Temperature Distribution}

It is interesting to examine the temperature profile which results from the balance between the heat flux from the plasma to the bed and, radiation and convective losses from the reactor wall.

A typical variation of the bed temperature as a function of time is schemed on Figure 2. The temperature in the bed increased rapidly with $\mathrm{N}_{2}$ plasma, then reach plateau about $30 \mathrm{~s}$. Thus the temperature distribution after 30 s would be considered as the steady temperature distribution. The temperature distribution in the reactor involves the energy exchange between the plasma gas and the entrained gas and solids from the spouted/fluidized bed. Radiant energy transfer also occurs and probably accounts for the major part of the heat transfer in a lateral direction away from the plasma. The transfer of energy from the plasma is an exceedingly complex process. In addition to convective heat transfer and thermal radiation, the energy transfer involves the mechanisms of Bremsstrahlung radiation due to the interaction of atoms and ions with free electrons, radiative recombination to ions and electrons, and the reversion from excited metastable states back to ground states. The extent of energy transfer by any one of these mechanisms depends greatly on the energy level and degree of ionization of the plasma, and no attempt was made in this study to examine their relative importance.

Typical temperature distributions obtained with operation condition of fluid gas $4 \mathrm{~m}^{3} / \mathrm{h}$ were shown in Figure 3. The map were plotted by interpolation on the basis of 25 thermocouple measurements. It may be note that, with

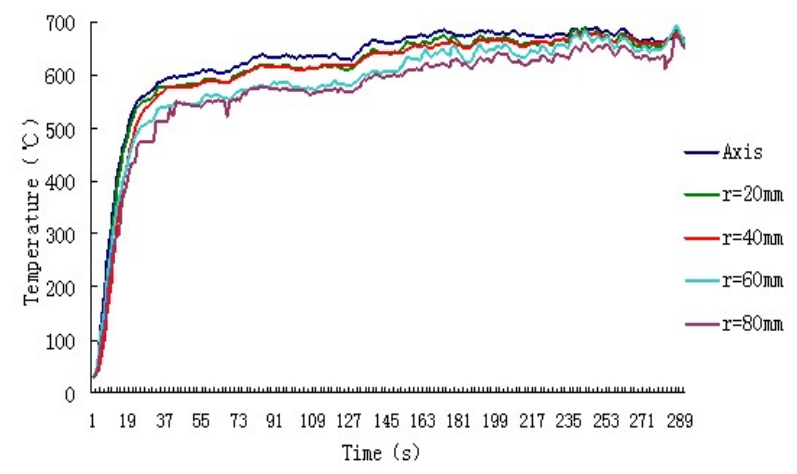

Figure 2. Typical variation of the bed temperature as a function of time at $z=300 \mathrm{~mm}$ (fluid gas $4 \mathrm{~m}^{3} / \mathrm{h}$, quartz sand $0 \mathrm{~g}$ and operation power $10 \mathrm{~kW}$ ). 
the exception of the region in the region in the immediate neighborhood of the fluid gas entrance, most of the remaining volume of the bed is at a reasonably uniform temperature which can be attributed to some extent to the high level of particle recirculation in the bed. Radial temperature differences are large, ranging from 200 to $300^{\circ} \mathrm{C}$, but axial temperature gradient are small; this observation indicates an efficient axial mixing due to the plasma jet but a poor radial diffusivity inside the annulus.

Thermal infrared imager images of quartz reactor wall at fluid gas $4 \mathrm{~m}^{3} / \mathrm{h}$ were shown in Figure 4. As noted earlier in this paper, one of the purposes of the fluid gas is cooling the reactor wall so as to decrease the radiation heat transfer between the reactor wall and surrounding. Compare the experiments' results, the level of the quartz wall temperature decreased significantly after increase the fluid gas.

\subsection{Energy Balance}

In order to evaluate the efficiency of the use of energy for carbonaceous organic material pyrolysis/gasification in the reactor, the amounts of energy required for reactions, enthalpy of exit products and heat losses must be

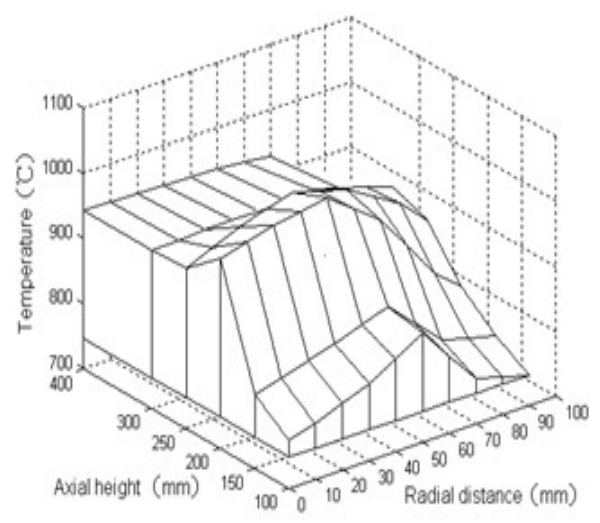

Figure 3. Temperature distribution in the reactor at fluid gas $4 \mathrm{~m}^{3} / \mathrm{h}$ (quartz sand $21.3 \mathrm{~g}$ and operation power $10 \mathrm{~kW}$ ).

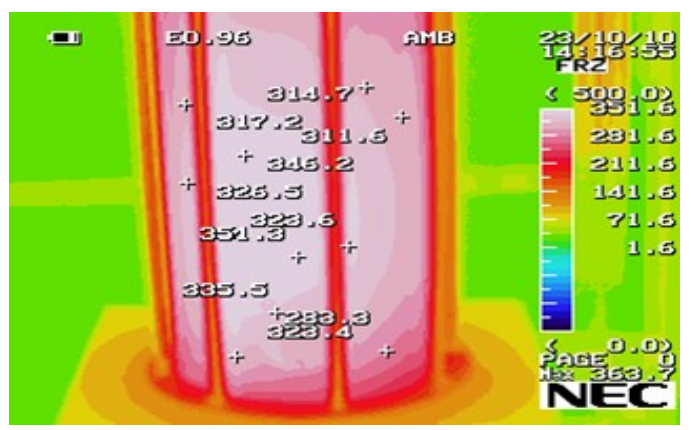

Figure 4. Thermal infrared imager image of quartz reactor wall at fluid gas $4 \mathrm{~m}^{3} / \mathrm{h}$ (quartz sand $21.3 \mathrm{~g}$ and operation power $10 \mathrm{~kW}$ ). determined. An energy balance on the reactor system including the basic losses in the plasma due to energy losses at the circuit is given as follows:

$$
\frac{m c \Delta T}{\Delta \tau}=Q_{\text {input }}-Q_{\text {losses-circuit }}-Q_{\text {losses-radiant }}-\frac{\Delta H_{\text {reaction }}}{\Delta \tau}-\frac{\Delta H_{\text {products }}}{\Delta \tau}
$$

where $m$ is cone-column pyrolysis reactor mass in $\mathrm{kg}$, $c$ is the reactor specific heat in $\mathrm{kJ} \cdot \mathrm{kg}^{-1} \cdot \mathrm{K}^{-1}, \Delta T$ is the temperature increase in $\mathrm{K}, \Delta \tau$ is the time interval of observation in seconds, the three $Q$ value are, respectively, rates of power supply inputs, losses to circuit and cooling water, and thermal loss, the enthalpy values are heats of formation of reactants and products.

Complete energy balance were attempted for two experiments, run 1 at input power $10 \mathrm{~kW}$ with fluid gas flow rate $4 \mathrm{~m}^{3} / \mathrm{h}$ and run 2 at input power $10 \mathrm{~kW}$ without fluid gas input, for the conditions of run 1 is the representative condition of gasification experiments, while the conditions of run 2 is the representative condition of pyrolysis experiments. Because the high heating rate of plasma, the reactor would be considered operating at steady state and the energy storage term would be zero. The rate of delivery of electrical energy to the system $Q_{\text {input }}$ was $10 \mathrm{~kW}$. By measure the cooling water inlet and outlet temperature and calculated the thermal loss taking by the cooling water, the value of $Q_{\text {losses-circuit }}$ in these two conditions had nearly the same value of 1.678 $\mathrm{kW}$. $Q_{\text {losses-radiant }}$ from the reactor is calculated by the reactor surface temperature and the environmental temperature. The reactor surface temperatures were estimated using the thermal infrared imager images.

For this is the preliminary experiment using the reactor, the fluid gas used in the reaction is nitrogen, while if using gasifying agent such as oxygen, water steam or air as the fluid gas, the content of the combustible gas in the product gas would increase due to the chemical reactions between the carbon and oxygen. Secondly, the flow rate of the gasifying agent (fluid gas) should adjust according to the feedback rate, and the fluid gas may be a bit more than that is needed. It is likely that future research in both fluid gas ingredient and flow rate will continue to improve the energy transfer efficiency of plasma spoutfluid systems.

In pyrolysis condition, the magnitude of the numbers about $36 \%$ show that a large percentage of the total energy delivered into the system is lost to circumstances, while the thermal loss was about $33 \%$ of total energy in gasification condition. The thermal losses of this laboratory reactor were still high, and the amount of energy used by the feedstock was small. This could be attributed to two reasons: 1) this laboratory reactor was a small scale apparatus having a large ratio of surface area/reactor volume; 2) in order to observe the plasma, transparent quartz tube was used for the reactor wall, which had in- 
creased the radiant heat loss. An industrialized scale system would allow a much higher proportion of the energy to be utilized. Then the ability to reduce the losses through the circuit and deliver more energy to the treatment of the feedstock is critical for economic feasibility of the technology.

\section{Conclusions}

The plasma spout-fluid bed reactor offers interesting characteristics as an efficient gas solid contactor which could find wide applications in the area of pyrolysis/gasification of solid carbonaceous material such as biomass and organic solid waste. Experimental data and an analysis of spout-fluid ability and thermal efficiency of a plasma spout-fluid bed reactor have been presented in this paper; over the range of experimental conditions investigated: the bed temperature distribution and stability are proper for biomass gasification and fluid gas would decrease the convective and radiant heat losses efficiently. Special attention should be given to the important question of particle attrition and the excessive elutriation of fine particles from the reactor which could represent an important problem.

\section{Acknowledgements}

We thank the support from the National Natural Science Foundation of China (51078092), "Yangcheng scholar" project of Education Bureau of Guangzhou (10A039G) and Guangzhou city-belonged university research project of Education Bureau of Guangzhou (10A020).

\section{REFERENCES}

[1] P. G. Rutberg, "Some Plasma Environmental Technologies Developed in Russia," Plasma Sources Sci. Technol., Vol. 11, No. 3A, 2002, pp. A159-A165. doi:10.1088/0963-0252/11/3A/324

[2] Z. Zhao, et al., "Biomass Pyrolysis in an Argon/Hydrogen Plasma Reactor," Chemical Engineering Technology, Vol. 24, No. 5, 2001, pp. 197-199.

[3] T. Inaba and T. Iwao, "Treatment of Waste by Dc Arc Discharge Plasma," IEEE Transactions on Dielectrics \& Electrical Insulation, Vol. 7, No. 5, 2000, pp. 684-692. doi:10.1109/94.879362

[4] K. Koutaro, et al., "Melting Municipal Solid Waste Incineration Residue by Plasma Melting Furnace With a Graphite Electrode," Thin Solid Films, Vol. 386, No. 2, 2001, pp. 183-188. doi:10.1016/S0040-6090(00)01640-0

[5] K.Seok-Wan, et al., " $100 \mathrm{~kW}$ Steam Plasma Process for Treatment of PCBs (Polychlorinated Biphenyls) Waste," Vacuum, Vol. 70, No. 1, 2003, pp. 59-66. doi:10.1016/S0042-207X(02)00761-3

[6] B. G. Ivan and I. M. Boris, "Some General Conclusions from the Results of Studies on Solid Fuel Steam Plasma Gasification," Fuel, Vol. 71, No. 8, 1992, pp. 895-901. doi:10.1016/0016-2361(92)90239-K

[7] K. E. Sherick and J. E. Findiey, "Energy and Costs Scoping Study for Plasma Pyrolysis Thermal Processing System," Energy Citations Database, G-WTD-9993,1992.

[8] P. Suwannakuta, "A Study on Biomass Gasification in Spout-Fluid Bed," Master thesis No. ET-02-22, Asian Institute of Technology, Bangkok, Thailand, 2002.

[9] R. J. Munz and O. S. Mersereau, "A Plasma Spout-fluid Bed for the Recovery of Vanadium from Vanadium Ore," Chemical Engineering Science, Vol. 45, No. 8, 1990, pp. 2489-2495. 